\title{
Renin-like Pressor Material in Ovarian Venous Blood of Pregnant Rabbits
}

\author{
Masamichi Oda and Tamotsu Fukuda \\ Department of Pharmacology (Prof. K. Tanaka), \\ Faculty of Medicine, Kyushu University, Fukuoka
}

\begin{abstract}
With isovolemic cross circulation method, a renin-like substance was found in the ovarian venous blood and also in the circulating blood in nonpregnant rabbits, though the content was lower than that of the renal venous blood. In pregnant rabbits, the content of the renin-like substance in the ovarian venous blood and circulating blood was about twice that of non-pregnant rabbits, whereas that in the renal venous blood remained unchanged. It is assumed that in pregnancy the renin-like substance increases significantly and this pressor material may suggest a uterine source of renin.
\end{abstract}

The presence of a renin-like pressor material in the placenta was first reported by Stakemann ${ }^{1}$ in 1960 and he showed that the placental renin was not derived from the systemic circulation. In 1966 , Gorden et al. ${ }^{2}$ reported that plasma renin activity was higher in pregnant than in non-pregnant rabbits and it correlated best with the uterine renin concentration. One of us $(1966)^{3}$ has also found a high content of the renin-like substance in the ovarian venous blood of pregnant rabbits. The present study was designed to define further the correlation between the ovarian renin-like substance and renal renin.

\section{Methods}

Rabbits of both sexes and of pregnancy, weighing $2.5-3.5 \mathrm{~kg}$, were used for the measurement of the renin-like substance in the systemic circulating blood, renal venous blood and ovarian venous blood.

In order to measure the renin-like substance in the blood of systemic circulating blood, isorolemic cross circulation technique was used according to the method developed by Schaechtelin et al. ${ }^{4}$ The indicator rabbit was nephrectomized under light ether anesthesia the day preceding the cross circulation experiment. The cross circulation was established by connecting the femoral arteries with the corresponding femoral veins of both animals (indicator and donor animals) and maintained at a constant flow (an average of 16-21 ml/ min) for $10 \mathrm{~min}$.

For the measurement of the renin-like substance in the renal venous blood or ovarian venous blood a special isovolemic cross circulation technique was used. The donor animal was anesthetized with subcutaneous injection of $1.2 \mathrm{~g} / \mathrm{kg}$ urethane and prepared in the following manner before establishing the cross circulation. As shown in Fig. 1, the whole left renal venous blood (or ovarian venous blood) was sent into the own circulation through a polyethylene catheter which had been introduced into the left renal vein (or ovarian vein) from the right femoral vein and connected to the left femoral vein via a blood

Received for publication, January 20, 1969. 


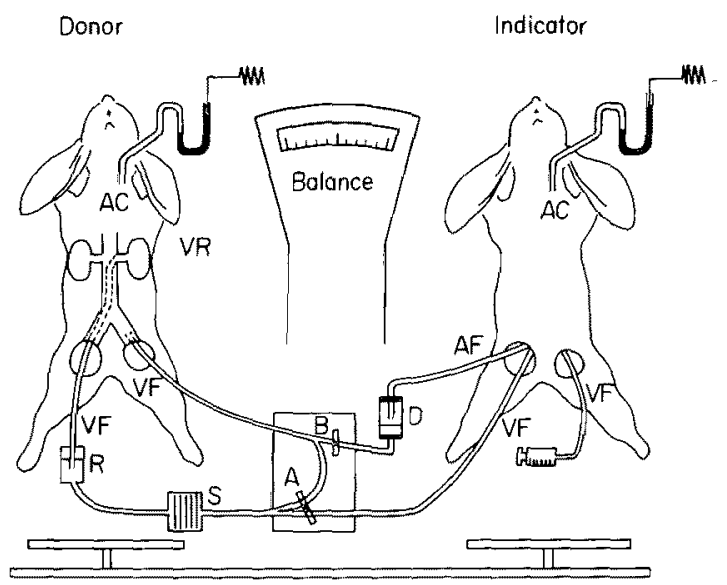

Fig. 1. Diagram of isovolemic oross circulation using the renal venous blood. $A$ and $B$ : screw cocks. AC: carotid artery. AF: femoral artery. VF: femoral vein. VR: renal vein. D: drop counter. R: blood reservoir. S: Sigma pump.

reservoir and Sigma pump. Since the catheter had been immediately opened at the same time of its insertion into the left renal vein (or ovarian vein), the renal or ovarian venous flow was not subjected to interruption throughout the operation. The indicator animal was bilaterally nephrectomized and anesthetized with urethane, and the femoral artery and vein were cannulated with catheters closed by clips in a manner similar to the general cross circulation method.

Both animals were then placed on a balance with a sensitivity of $\pm 50 \mathrm{mg}$. Subsequently the cross circulation was established by connecting each vessel of the partner. Isovolemia was controlled by the balance and could be regulated by adjusting screw clamps ( $\mathrm{A}$ and $B$ in Fig. 1) placed on both connecting tubes between two animals. Screw clamp A was so designed that remaining blood from the renal vein was still sent into the own circulation of the donor animal, until the whole left renal venous blood of the donor animal was completely sent to the indicator animal without any interruption. The cross circulation was maintained for $10 \mathrm{~min}$, a period sufficient for the exchange of the total blood volume of both animals, and the flow measured by a drop counter (D in Fig. 1) was 17-22 $\mathrm{ml} / \mathrm{min}$ on the average in the experiments with the renal venous blood and $15-18 \mathrm{ml} / \mathrm{min}$ in those with the ovarian venous blood.

In all experiments, the sensitivity of indicator animals to angiotensin II was tested by intravenous injection of a standard dose of $0.02 \mu \mathrm{g} / \mathrm{kg}$ before establishing the cross circulation. Only animals which reacted to angiotensin with an increase of 15-16 $\mathrm{mmHg}$ of blood pressure were used. The content of the renin-like substance in the blood was indicated with the height of sustained and irreversible blood pressure elevation, which occurred in the indicator animal by the cross circulation. Heparin sodium was also used to prevent blood coagulation.

\section{Resulits}

By cross circulating an intact non-pregnant rabbit with a nephrectomized indicator animal, the renin-like substance was found in the blood of systemic circulation of non-pregnant rabbits of both sexes as shown in Table 1, producing an irreversible and sustained elevation of blood pressure in the indicator animal. The blood of systemic circulation from nephrectomized donor rabbit did not cause 
TABLE 1. The average blood pressure increase in nephrectomiced indicator rabbit in cross circulation experiments (5 rabbits per group)

\begin{tabular}{|c|c|c|c|c|}
\hline \multicolumn{2}{|c|}{ Donor animals } & $\begin{array}{l}\text { Systemio } \\
\text { circulating }\end{array}$ & Renal & Ovarian \\
\hline \multirow{2}{*}{ Non-pregnant } & Male & $10.8 \pm 0.4$ & $18.4 \pm 0.8$ & \\
\hline & Female & $* 11.2 \pm 0.6$ & $* 15.4 \pm 2.2$ & $11.2 \pm 0.8$ \\
\hline \multicolumn{2}{|l|}{ Pregnant } & $22.6 \pm 0.6$ & $+17.2 \pm 1.2$ & $\dagger 24.8 \pm 1.4$ \\
\hline \multicolumn{2}{|c|}{ Nephrectomized female } & $0.8 \pm 0.8$ & & \\
\hline
\end{tabular}

Numerals show the average blood pressure increase $(\mathrm{mmHg}) \pm \mathrm{SE}$.

$*: \mathrm{P}<0.05 . \quad+: \mathrm{P}<0.005$.

any blood pressure rise in the indicator animal. By the cross circulation using the ovarian venous blood of non-pregnant animals, a similar pressure rise in the indicator animal was noted, and the pressure did not either return to the control level after interruption of the cross circulation. In the case of the renal venous blood under the same experimental conditions, however, elevated blood pressure in the indicator animal was higher than that caused by the circulating blood or even ovarian venous blood (Table 1).

In the rabbits on the 26 th day of pregnancy, the cross circulation using the blood of systemic circulation of such an animal with a nephrectomized indicator animal caused a marked and prolonged elevation of blood pressure which was about twice the value found in non-pregnant rabbits, and this significant increase of blood pressure in the indicator animal was also found in the cross circulation using the ovarian venous blood as shown in Table 1 . The significantly high blood pressure did not return to the control level after the cross circulation was interrupted. The renal venous blood in pregnancy caused also a prolonged elevation of blood pressure in the indicator animal by the cross circulation, and this value was

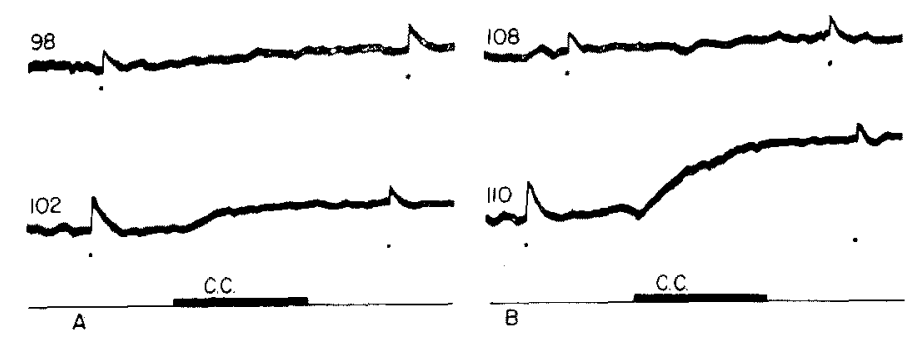

Fig. 2. Blood pressure change caused by cross eirculation using the ovarian venons blood of a donor rabbit ( $A$ : non-pregnant donor, $B$ : pregnant donor).

The lower trace shows the blood pressure of a nephrectomized indicator and the upper trace shows that of a donor. Cross circulation (C.C.) was maintained for $10 \mathrm{~min}$ and the flow was $16 \mathrm{ml} / \mathrm{min}$ in the case of $\mathrm{A}$ and $17.2 \mathrm{ml} / \mathrm{min}$ in the case of $\mathrm{B}$. At the black points, angiotensin II was injected intravenously $0.02 \mu \mathrm{g} / \mathrm{kg}$ to the indicator animal and $0.16 \mu \mathrm{g} / \mathrm{kg}$ to the donor animal. 
almost the same as that in non-pregnant animals. Fig. 2 shows irreversible and sustained blood pressure increase due to the cross circulation using the ovarian venous blood of non-pregnant and pregnant rabbits.

\section{DISCUSSION}

On the pressor material in the placenta, as well as pregnant and nonpregnant uterus of rabbits, Gross et al. ${ }^{5}$ reported the existence of a principle which was comparable to renin. Ferris et $a l .^{6}$ and Gorden et $a l .^{2}$ also reported a high concentration of a renin-like substance with several characteristics of renin in the pregnant rabbit uterus and the elevation of plasma renin activity in pregnancy. In pregnant women, Brown et al. also found a higher concentration of plasma renin than that in non-pregnant subjects ${ }^{7}$ and moreover, the concentration of renin in the amniotic fluid was also higher than that in serum. ${ }^{8}$

The present study showed that in pregnant rabbits, the renin-like substance in the ovarian venous blood and even in the circulating blood increased significantly. Generally, it is assumed that renin contained in extrarenal organs and in plasma is produced in the kidney. Our findings also demonstrated that the content of the renin-like substance of renal venous blood in non-pregnant animals was a little higher than that of the normal blood of systemic circulation and of ovarian venous blood $(\mathrm{P}<0.05)$. However, the content of the renin-like substance of the renal venous blood in pregnancy was almost the same with that in non-pregnant female rabbits, whereas that of the ovarian venous blood and circulating blood markedly increased. This suggests the possibility that in pregnancy a large amount of renin-like substance may be released into the ovarian vein, and it may be explained by a uterine source of renin, independent of the kidney. Gorden et al. ${ }^{2}$ and Ferris et $a l .^{6}$ also suggested that the plasma renin activity in pregnant rabbits correlated best with the uterine renin concentration, ${ }^{2}$ and that pregnant uterus was a greater potential source of renin than the kidney and the uterus was the site of renin synthesis. 6,9 The present findings may support their view. Moreover, the present result that there was a little difference between the content of the renin-like substance in plasma and that in the renal venous blood of pregnant rabbits $(\mathrm{P}<0.025)$ may suggest that a kind of negative feedback effect of circulating angiotensin on renin secretion in the kidney is elicited under these circumstances.

\section{References}

1) Stakemann, G. A renin-like pressor substance found in the placenta of the cat. Acta path. microbiol. scand., 1960, 50, 350-354.

2) Gorden, P., Ferris, T.F. \& Mulrow, P.J. Studies of uterine renin. J. clin. Invest., $1966,45,1015$.

3) Oda, M. Release of renin-like substance from ovarial vein of the pregnant rabbits. Nippon Yakuri Gaku Zasshi (Jap.), 1966, 62, 157--158§.

4) Schaechtelin, G., Regoli, D. \& Gross, F. Bio-assay of circulating renin-like pressor material by isovolemic cross circulation. Amer. J. Physiol., 1963, 205, 303-306. 
5) Gross, F., Schaechtelin, G., Ziegler, M. \& Berger, M. A renin-like substance in the placenta and uterus of the rabbit. Lancet, 1964, 1, 914-916.

6) Ferris, T.F., Gorden, P. \& Mulrow, P.J. Rabbit uterus as a source of renin. Amer. J. Physiol., 1967, 212, 698-702.

7) Brown, J.J., Davies, D.L., Doak, P.B., Lever, A.F. \& Robertson, J.I.S. Plasmarenin in normal pregnancy. Lancet, 1963, 2, 900-901.

8) Brown, J.J., Davies, D.L., Doak, P.B., Lever, A.F. \& Robertson, J.I.S. The presence of renin in human amniotic fluid. Lancet, 1964, 2, 64-66.

9) Gorden, P., Ferris, T.F. \& Mulrow, P.J. Rabbit uterus as a possible site of renin synthesis. Amer. J. Physiol., 1967, 212, 703-706. 